\title{
DE TOPONIMIA HISPALENSE
}

\author{
María Dolores Gordón Peral
}

1. Es a D. Vicente García de Diego López a quien debemos el primer estudio de conjunto sobre los nombres de lugar de Sevilla y su provincia ${ }^{1}$. Ha transcurrido ya más de un cuarto de siglo desde que su artículo viera la luz, y en ese amplio espacio de tiempo no le ha secundado ningún otro trabajo sobre toponimia sevillana ${ }^{2}$, lo cual puede explicarse por el olvido manifiesto a que se viene condenando la Ciencia Onomástica entre los estudiosos de esta región o, en cualquier

1 «Estudio histórico-crítico de la toponımia mayor y menor del Antiguo Reino de Sevilla», separata de Archivo Hispalense, n. 97 (1959) —citado Estudio-.

Las abreviaturas bibliográficas citadas en lo que sigue son:

Contribución

$D E C H$

Estudis

Tópica

Donadios

Madoz

$D L E$

Manual

Origenes

Toponimia Prerr.

Toponimia Áv.
M. Asín Palacios: Contribución a la toponimia árabe de España, C.S.I.C., Madrid, 1940.

J. Corominas-J.A. Pascual: Diccionario crítico etimológico castellano e hispánico (4 vols.), Gredos, Madrid, 1980-83.

J. Coromines: Estudis de toponimia catalana, vol. I, Barcino, Barcelona, 1965.

J. Corominas: Tópica hespérica, vol. I, Gredos, Madrid, 1972.

M.A. Ladero: «Donadíos en Sevilla. Algunas notas sobre el régimen de la tierra hacia 1500», en Archivo Hispalense, n. 181 (1976), pp. 19-91.

P. Madoz: Diccionario Geográfico Estadístico Histórico de España y sus posesiones de Ultramar (16 vols.), Madrid, 1846-50.

R. Menéndez Pidal: Documentos Lingüísticos de España, vol. I, Centro de Estudios Históricos, Madrid, 1919.

R. Menéndez Pidal: Manual de Gramática Histórica Española, Espasa-Calpe, Madrid, 1980 (16 ${ }^{\mathrm{a}}$ ed.).

R. Menéndez Pidal: Orígenes del Español. Estado lingüístico de la Península Ibérica hasta el siglo XI, Espasa-Calpe, Madrid, 1980 (9. ed.).

R. Menéndez Pidal: Toponimia Prerrománica Hispana, Gredos, Madrid, 1968. E. Tejero Robledo: Toponimia de Ávila, Diputación Provincial, Ávila, 1983.

2 Nos referimos a la total ausencia de investigaciones de relativo peso en torno a la onomástica de lugares de la provincia. Para los varios estudios parciales, referidos a determinados aspectos de la corografía sevillana - que en su mayoría corresponden a parcelas extralingüísticas-, véase nuestro artículo «La Ciencia Onomástica en el Mediodía hispánico. Trabajo realizado y trabajo por realizar» (en prensa). 
caso, por considerarse suficientemente cubierto el vacío anterior en torno al conocimiento de la corografía antigua y moderna de Sevilla ${ }^{3}$.

1.1. En el prólogo a su obra, D. Vicente reconoce que se trata de un «pequeño estudio susceptible de ampliación y perfeccionamiento, por poseer más material»; y continúa: «comprende los nombres de los pueblos, aldeas, cortijos y, en general, accidentes geográficos del Antiguo Reino de Sevilla; en suma, lo que se llama la toponimia mayor y menor». A lo que se ve, él mismo comprendía las limitaciones de su empeño, y quizá también entreviera el riesgo que comportaría el someter una obra de tan grandes proporciones a los estrechos márgenes de un artículo, por amplio que fuese. No obstante, en modo alguno ello fue óbice para que llevase a término la empresa, de la que esperaba «recoger apreciaciones de conjunto muy provechosas» ${ }^{4}$.

1.2. Sería realmente injusto cuestionar el mérito de este trabajo, que, de otro lado, fue sobradamente reconocido en su día ${ }^{5}$. Además de que globalmente sigue teniendo validez, resulta sumamente valioso por recoger en su parte inicial (pp. 2-12) abundante bibliografía, tanto de carácter histórico y geográfico en general, como lingüístico y onomástico en particular. Merecen destacarse, asimismo, los datos referentes a documentación antigua, aunque no siempre se utilicen de manera provechosa, dado que, en la mayoría de las ocasiones, se acumulan o superponen varias formas antiguas donde debiera darse la explicación de la moderna - que constituye la entrada en cuestión-, sin otra justificación lingüística ${ }^{6}$.

1.3. Sin embargo, el estudio de García de Diego acusa determinados defectos que precisan de una revisión sistemática. Tales son los que derivan de la inadecuación de método - elección de fuentes de información fidedignas, principalmente $-{ }^{7}$, esto es, la inexactitud en la localización de las formas toponímicas ac-

3 Visto el desolador cuadro que presenta la investigación onomástica en esta región, resulta loable la iniciativa tomada por la cátedra de Historia de la Lengua Española de la Universidad de Sevilla, en la labor de recolección de topónimos andaluces por términos municipales. No obstante, aún es mucho lo que queda por hacer, y el camino se vería allanado si se contase con un mayor apoyo por parte de las instituciones provinciales y regionales, que podrían financiar el coste material de la tarea.

4 Véase la página introductoria.

5 De hecho, como consta al final (p. 107), obtuvo el premio en el Concurso de Monografías convocado en 1958.

6 Véase, a título ilustrativo, el análisis del topónimo Alcoraxi: «Alcoraxi. En San Lúcar (Solúcar). Machar de... Llamada Palençiola por heredarla el obispo de Palencia» (Estudio, p. 57). Tómese en consideración, además, que en la redacción del trabajo faltan tanto acentos como signos de puntuación, subrayados, etc., que hacen prácticamente ininteligible el texto; por ello hemos preferido añadirlos a la hora de transcribir sus partes.

7 De la metodología más apropiada y científicamente válida en la elaboración de un corpus toponomástico fidedigno, basada fundamentalmente en la encuesta oral, el despojo de materiales del Catastro y de la documentación medieval (fuentes dejadas al margen por García de Diego), nos ocupamos por extenso en el artículo citado en la nota 2. 
tuales y la falta de exhaustividad general en la recopilación del corpus ${ }^{8}$. Pero tal revisión sólo sería dable en un estudio detenido - que partiese de otros presupuestos metodológicos-, y, por supuesto, de mayor magnitud que la de un artículo $^{9}$. Otro tipo de defectos, más susceptible de corrección a corto plazo, es el de los errores en la interpretación etimológica. A la enmienda de algunos de ellos dedicamos este trabajo, en el que, tomando por base el juicio de García de Diego, procederemos a proponer una nueva justificación de la forma estudiada a partir de la confrontación con otra u otras formas posibles - cuando las haya-, o a partir de un étimo desconocido para el autor ${ }^{10}$. Tendremos muy en cuenta para algunos casos la documentación medieval, rechazada, según parece, por D. Vicente, que se justifica porque «el documento medieval falsifica la forma por latinizar los nombres» (?) ${ }^{11}$.

AGUALORA.- «Compuesto de dos sustantivos» - se supone agua + lora(Estudio, p. 56). Lleva asterisco por considerarlo topónimo desaparecido o cambiado ${ }^{12}$.

Etimología popular a partir de un probable *Guadalora, de wādī ár. 'río' y Lora, topónimo que aparece como primer componente de los compuestos Lora del Río, Lora de Estepa, quizá de un antropónimo *LAURA $<$ LAURUS, «cognomen céltico que aparece en inscripciones españolas» (Menéndez Pidal, Toponimia Prerr., p. 133) ${ }^{13}$.

Resulta extraño que García de Diego no reconozca la etimología popular en este caso; lo hace, en cambio, con Aguaderilla < Guadairilla, Sanlúcar < Solúcar, Cuatrohabitan < Cotrovita, Espera $<$ Experem (Estudio, pp. 15-16). Añadimos a éstos un ejemplo de doblete que aparece en distintos lugares de un mismo documento sevillano: Agua del Peral y Guadalperal (1506: «laguna del guadalperal»; «laguna del agua del peral» ${ }^{14}$, curiosamente paralelo al analizado aquí, ambos de sentido hidronímico.

8 De Alanís, por poner un ejemplo indicativo, se dice que está situada «en Guadalcanal»; de San Nicolás del Puerto, por poner otro, que se localiza «en Alanís», cuando, como bien se sabe, no son sino tres poblaciones independientes (por más que sus términos sean colindantes), y lo han sido desde siempre.

9 A esta materia - y no por un hecho fortuito y reciente- dedicamos nuestra tesis doctoral, en la que retomamos el corpus aportado por D. Vicente y lo sometemos a una nueva dimensión crítica, añadiendo tantos otros datos de indudable valor histórico-lingüístico.

10 Se tratará, ante todo, de ofrecer el ineludible aparato crítico de que carece el Estudio, que servirá de apoyo suficiente al étimo postulado.

11 No comprendemos bien qué tipo de latinismos podrán aparecer en los documentos medievales andaluces, pertenecientes a una fecha tan tardía de la historia del idioma; en todo caso, surgirán grafías arabizadas, que de hecho son utilísimas a la hora de descifrar la toponimia andaluza.

12 Véase la p. 1 del Estudio.

13 Cf. s. v. Lora de Estepa, ibíd., p. 83. La vecindad de los lugares así nombrados obliga a descartar un origen diferente para cada uno de ellos, aunque García de Diego opine lo contrario.

14 Es un documento que narra las «pesquisas y relaciones de los jueces de términos, Licenciados Maluenda y Vázquez Dávila, sobre régimen de aprovechamientos comunales en donadíos, usurpación de tierras comunales y pleitos de términos pendientes o sentenciados en Sevilla y su «tierra»: Archivo General de Simancas. Diversos de Castilla, leg. 42, doc. 75 (M. A. Ladero, Donadíos, p. 46). 
ALANÍS.- «Tiene origen discutido: del bretón alanig 'zorro', o del pueblo de los álamos o del ár. al-anis (Asín P.)» (Estudio, p. 56).

Macrotopónimo con localización errónea en García de Diego ${ }^{15}$. Ha sido objeto de filiaciones tan extravagantes como las dos primeras citadas arriba, o incluso como la de ser derivación del gentilicio alanos, pueblo de estirpe visigótica al que se atribuye el cambio de nombre de la antigua ciudad de Ancanicum por el que lleva en la actualidad. Más razonable resulta la propuesta del arabista M. Asín Palacios, quien incluye Alanís en su «lista de topónimos probable o seguramente arábigos, no descifrados todavía», es decir, cuya etimología no ha logrado encontrar, aunque espera que posibles documentos antiguos, no manejados por él, denuncien mejor su prototipo originario ${ }^{16}$. En efecto, parece seguro que $A l a-$ nís contiene el artículo árabe $a l$, que acompaña de modo inherente a los apelativos arábigos — según el tratamiento romance popular ${ }^{17}$-, mas no está tan clara la supuesta filiación oriental del segundo elemento [Al]anis ${ }^{18}$, que, de modo más sencillo, podría tratarse del cast. anís (resultando una formación híbrida arábigo-romance) ${ }^{19}$. Ante la incertidumbre, lo único que cabe asegurar es que el topónimo presenta una forma similar a la de otros muchos procedentes de nombres comunes árabes (Alaraz, Alarza, Alariza, Alocaz, Alange, etc.) ${ }^{20}$, que no llegaron a incorporarse al romance, sino que, como fósiles, no poseen hoy más sentido que el estrictamente geográfico, y característicos, sobre todo, del que fue territorio de la España musulmana.

En documento de 1386 aparece el nombre de lugar con la forma moderna: «conçeio de alanis»; "conceio de alanis» ${ }^{21}$. Lo mismo ocurre en los de fecha posterior: 1461: «logar de alanis»; 1541: «villa de alanis» ${ }^{22}$.

15 Véase la nota 8 de este artículo.

16 Contribución, p. 147. La primera documentación conocida del topónimo data de 1392, y ya aparece en la forma actual. Sin embargo, en el sello que figura en tal documento, de fecha más tardía (1437), se alude al «conceio de allanis», en divergencia con el resto de los textos de la misma época -que dan unánimemente alanis -, o incluso con los que hacen referencia a nombres de persona que incluyen tal topónimo. Véase nuestro artículo «La antroponimia en Guadalcanal según documentos inéditos de los siglos XVI, XVII y XVIII», en Actas del Primer Congreso Internacional de Historia de la Lengua Española (Cáceres, 30 de Marzo-4 de Abril de 1987), en prensa.

17 Véase J. Oliver Asín, En torno a los orígenes de Castilla. Su toponimia en relación con los árabes y los beréberes, Real Academia de la Historia, Madrid, 1974, p. 43.

18 Ignoramos la justificación de la seguridad con que algunos historiadores establecen el étimo musulmán al-anís 'el afable' (véase F. Collantes de Terán y otros, Catálogo Arqueológico y Artístico de la provincia de Sevilla, Diputación Provincial, t. I, p. 22), aunque desde luego menos fabuloso que algunas otras explicaciones que circulan por las revistas de difusión local.

$19 \mathrm{Al}$ estilo de los muchos topónimos que añaden a una voz romance el artículo árabe: Almonaster, Almonacid, Almonte, Alpuente, Alportel, según R. Lapesa (Historia de la Lengua Española, Gredos, Madrid, 1981 (9. ed.)).

20 Cf. M. Asín, Contribución, s. vv.

21 Archivo Municipal de Sevilla, Papeles del Mayordomazgo (véase Catálogo Arqueológico..., p. 234).

22 Archivo Municipal de Sevilla, Actas Capitulares, fs. 95-97 r (cf. M. González Jiménez, «El concejo de Alanís en el siglo XV», Archivo Hispalense, núms. 171-173 (1973)) y Becerro de 1541 del Archivo Municipal de Alanís. 
ALÍSAR.- «Sufijo colectivo de aliso, del celta *alisia o bien de alixar (otra evolución alíjar) del ár. al-dixar 'erial'». Topónimo menor del término de Castillo de las Guardas (Estudio, p. 58).

Asín Palacios no menciona más que nombres de lugar de las formas Alíjar (seguramente arábigo; en Cádiz) y Alija (probable, no seguro; en Cáceres y León), el primero de los cuales relaciona con el Benalijar de Sevilla (actual hidrónimo), ambos significando 'las piedras' —en el segundo caso, 'el de las piedras' o 'casa de las piedras' - ${ }^{23}$. Oliver Asín, en cambio, recoge varios nombres de lugar Alija y un Gualija o Guadalija (todos de Cáceres), al parecer documentados en historiadores árabes bajo la forma $A l i \bar{s} s a$ y correspondientes a lugares donde se asentó la tribu beréber de los cebrones ${ }^{24}$.

Puede ser que el topónimo Alísar no sea más que un resultado no palatal del ár. al-hiŷar, origen tanto del Alíjar gaditano como del Benalíjar (arroyo próximo a la zona donde se encuentra el despoblado al que prestamos atención) de Sevilla. Véase aquí el artículo BENALÍJAR.

BADOLATOSA.- «Puede ser de Val de la Tosa, de tonsa 'calma', o quizás de Badela tonsa 'espaldar pelado', que recuerda al tegum lat.» (Estudio, p. 61).

Verdaderamente revelador, para descartar tales hipótesis y hallar el étimo más verosímil, resulta el topónimo Badlaïtouze «vallée et pic des Pyrénées gasconnes», que J. Corominas ${ }^{25}$ compara con otras formaciones del tipo: Eina (vallée d'Eina), en la Cerdaña francesa, «vers les sources du Sègre, étant exposée au Nord et parmi les plus vertes et fraîches de Cerdagne et les vaches y abondant excessivement» y Esnoz (pueblo), en Navarra, ambas explicables por el vasco ezna o ezne 'leche'. Más estrecha conexión con la analizada guardan las otras formas toponímicas romances Pla de Llet, Fontlletera, Les Lleteres, Llitera (<Lleitera), todas ellas de Cataluña; Literola, Letosa, de Aragón; Leitoego, de Galicia; Leitariegos, de Asturias; Leite y Leitões, de Portugal. Pueden añadirse aquí otros topónimos no citados por el etimólogo catalán y que el maestro Pidal comenta en diferente sentido: Litago (sin localizar) y Lituego (en Zaragoza) ${ }^{26}$.

No podemos afirmar nada rotundamente respecto de la base originaria del nombre de lugar que nos ocupa, pues para ello se precisaría de la documentación antigua, de la que no disponemos. De ahí que, por el momento, tengamos que conformarnos con un hipótetico *VALLIS LACTOSA, cuyo primer componente, originariamente femenino, explicaría la terminación del topónimo (-osa), injustificable si se tratase de un étimo *VADUM 'vado'. Acaso la desemantización del topónimo fuera motivo de una especie de etimología popular - lo cual sería extensible a la formación gascona, práctico calco de la andaluza-; por ella se entendería *Val-de-la-tosa (cf. supra, Estudio, p. 61), o bien *Vado-de-la-tosa,

23 Contribución, s. vv.

24 En torno a los orígenes de Castilla..., p. 32.

25 En su artículo «La toponymie hispanique préromane et la survivance du basque jusqu'au bas Moyen Âge (Phénomènes de bilinguisme dans les Pyrénées Centrales)», en VI Internationaler Kongress für Namenforschung (H. von Gerhard Rohlfs), München: 24. 28 August 1958, pp. 105-146.

26 Toponimia Prerr., pp. 218, 266. 
*Vado-de-la-latosa. Con respecto a la forma culta [Bado] la(i)tosa (que en evolución normal castellana hubiese resultado lechosa, con palatalización del grupo ait), debe suponerse de carácter dialectal, por lo que será forma importada por repobladores - de origen oriental, probablemente-o, más raramente, autóctona y de raigambre mozárabe. Téngase en cuenta que al sur de Sevilla también, en término de Montellano, se localiza un topónimo Laita (véase aquí, s. v. LAITA) ${ }^{27}$.

BAHONDILLO.- «Del bafondillo del lat. bafondellus, cruce del lat. bassus ‘bajo' y fundus 'hondo'». Nombre de una dehesa del término de Aznalcóllar (EStudio, p. 61).

La etimología de García de Diego se admite y repite en la obra de E. Tejero Robledo ${ }^{28}$ para el topónimo abulense Bajoncillo, a todas luces etimológicamente diferente (en cualquier caso, y por válida que resultase la explicación para el Bahondillo sevillano, sería inútil para justificar una forma que no es otra que un derivado por sufijación e infijación del romance cast. bajo; lo que ocurre es que E. Tejero confunde la cita, tomando Bahoncillo por Bahondillo).

Parece más acertado partir de un *Valhondillo $<*$ VALLIS FUNDUS-ELLUS (cf., supra, Badolatosa) o de un *Va(d)o-hondillo $<*$ VADUM íd., de donde $V a$ hondillo, grafiado modernamente Bahondillo. (Cf. Badalbuey, de *Va(do)-delbuey, o quizás de *Val-del-buey $>* V a l d a l b u e y>V a d a l b u e y ;$ véase Estudio, p. 61). Y eso, debido a que, de haberse dado la evolución desde una base *bafondillo (<lat. *BAFONDELLUS < lat. BASSUS FUNDUS-ELLUS), lo más seguro es que hubiera resultado una aspiración e, incluso, velarización, del tipo *Bajondillo (dada la marcada tendencia a aspirar en las hablas andaluzas ${ }^{29}$ ), pero jamás un Bahondillo. De otro lado, en documentos antiguos está ya atestiguada la pérdida de la - $d$ - en la forma vado, lo que puede constituir un dato más a favor de la interpretación propuesta aquí; así, en texto sevillano de 1506 alternan las formaciones corográficas «donadio de bao» y «donadio del vado», tal vez refiriéndose a un mismo lugar ${ }^{30}$.

BAILÉN, EL.- «Etimología no conocida». Topónimo menor de La Puebla de Cazalla (Estudio, p. 61).

Sea autóctono o importado, se trata, aparentemente, de un diptongo mozárabe ail (que detendría la evolución de $l i$ ), «acaso de $\mathrm{V}$ a 1 i u s», según Pidal origen de los franceses Vailhan, Vaillac ${ }^{31}$, ahora con sufijo -én de pertenencia ${ }^{32}$. Es la explicación del maestro para la forma toponímica jiennense, que puede tenerse como válida para la de Sevilla, aún cuando esta última parezca presuponer

27 Véase también, en esta entrada, el comentario efectuado en orden a la conservación de los diptongos arcaicos en estos nombres de lugar.

28 Toponimia Áv., pp. 102-103.

29 Véase a este respecto J. A. Frago Gracia, «Materiales para la historia de la aspiración de la /-s/ implosiva en las hablas andaluzas», Lingüística Española Actual, V (1983), pp. 153-171.

30 Cf. Donadios, pp. 53 y 61.

31 Toponimia Prerr., p. 124.

32 «Bailén pudiera asociarse a éstos, suponiéndolo influido por la pronunciación oficial culta que mantuvo $l i$ + vocal sin palatalización de $l$, y permitió la atracción de yod a la sílaba con $a$ acentuada» (ibid.). 
un antropónimo y una construcción de tipo posesivo: $E l$ (sitio, lugar de) Bailén . (Cf. el característico sintagma toponímico Lo (de) + antropónimo o topónimo: Lo (de) Cristión, Lo Borja - 'el campo o la tierra de Cristión', 'el término de Borja'- ${ }^{33}$.

BENALÍJAR.- «Del ár. ben 'árbol' y alíjar o 'erial', de al-dixar, sería 'el árbol del erial'. Bien del lat. penna illisa 'peña intacta', o del ár. ben-al-hixen, antropónimo» (Estudio, p. 63).

Actual hidrónimo con localización imprecisa en García de Diego, que repite la voz s. v. ribera (p. 96), añadiendo: «Ben-alíjar [?] se halla en Cádiz y Toledo [y] puede ser Hixen».

En realidad, se trata del nombre de una rivera o arroyo que nace en el término de Alanís, «camina de NO á S hasta unirse con la de Viar, que va a parar también al Guadalquivir», según explica Madoz ${ }^{34}$. Etimológicamente puede ser un antropónimo, o quizá topónimo, de procedencia árabe; el problema reside en su carácter de compuesto, pues la mixtura de formas entorpece la concreta identificación originaria: si se piensa en el prefijo frecuente en la onomástica árabe ben-, de $i b n$ 'hijo de', Benalíjar sería *Ibn-Alhiŷar 'el de las piedras', apodo o sobrenombre de persona. Pero cabe la posibilidad de que se trate de un topónimo compuesto del ár. bina 'casa', con lo que significaría 'casa de las piedras'. Es la última la interpretación que prefiere Asín Palacios, quien recoge otros topónimos compuestos de tal apelativo (bina/bena) y otro término arábigo, en algún que otro caso un nombre propio de persona: Benacazón, Benagalbón, Benajéber, Benaha$l i$, etc. ${ }^{35}$.

BONAGIL.- «Término mozárabe, de bona-Agilii o de Ben-Agilii» (Estudio, p. 64).

Para comprender mejor el topónimo — sin localización en el Estudio-, es preciso confrontarlo con otros que aparecen en la misma provincia: Benajila o Benagila ${ }^{36}$, Frontegil, Montegil (citados por García de Diego) y Huenagil ${ }^{37}$, nombres de despoblados los tres primeros, e hidrónimo el último. Sería demasiada

33 Véase J. A. Frago Gracia, Toponimia del Campo de Borja. Estudio Lexicológico, Institución «Fernando el Católico», Zaragoza, 1980, p. 88 (citado en mi Toponimia de la Sierra Norte de Sevilla. Estudio Lexicológico, Publicaciones de la Universidad de Sevilla —en prensa-).

34 Diccionario..., s. v. Alanís.

35 Véase aquí, s. v. ALÍSAR, la opinión de otro arabista, J. Oliver Asín, en cuanto a los topónimos de estas formas. En concreto, su tesis se basa en tomar el radical Alija como un $\supset_{A} i \bar{s} a$, nombre de un río Gualija o Guadalija, un despoblado, una sierra, un castillo en ruinas (todo ello en el contorno de Talavera la Vieja (Cáceres), juicio apoyado en el testimonio de topónimos con esta forma desde Astorga hasta el sur de Badajoz, territorio que cruzaba la llamada Vía de la Plata, donde se hallan nombres de lugar como Cebrones, precisamente gentilicio romance en plural de Șabrun, tribu beréber que gobernó Alǐ̌ $a$ - según cuenta el historiador Ibn Hazm en su Ŷamhara-. Distinto étimo propone para la raíz Alija J. Corominas (Tópica I, p. 100, nota 31), quien piensa en un *ALISCIA mejor que en el ya postulado *ALISĀNTIA.

36 Benajila está en García de Diego López (Estudio, p. 63); Benagila, en documento sevillano de 1506 (cf. Donadíos, p. 55).

37 Rivera del término de El Pedroso documentada en Madoz (s.v. Pedroso) e ignorada por el autor del Estudio. 
coincidencia esta abundancia de nombres de lugar en un territorio relativamente pequeño, si no respondiesen - como parece creer D. Vicente ${ }^{38}$ - a una misma etimología. Es verdad que Montegil puede adjudicarse a un *MONTICELLUS, siendo su terminación típicamente mozárabe ${ }^{39}$, pero creemos imposible que $\mathrm{Be}$ najila proceda de Benalíjar (cf. supra y Estudio, p. 63) por metátesis, o que Frontegil deba su segundo componente a un «equile (cabeza de caballo), en Lérida guils» (ibíd., p. 68). (¿Qué explicación buscaría el autor para Huenagil, de haber tenido información del hidrónimo?). De otra parte, habría que colocar junto a los mencionados las formas corográficas Gila, Gilena, Gilete y Guillena (ant. Gilien $a^{40}$ ), claro es, descartando para la primera el lat. GILVA postulado por García de Diego (Estudio, p. 80). Todas ellas bien pudieran remitir al germánico Egila, con sufijo femenino -ilo (variante documentada Agilo), antropónimo tan frecuente en la documentación medieval-Egila aparece en doc. de Sahagún de a. 916; Agilo, en el mismo lugar, a. 930, donde también Egilo, a. 941 y $963^{41}$. El mismo M. Asín Palacios puede corroborar la anterior propuesta, pues en su Contribución (s. v. Almonte), explica: «Yāqūt (...) registra seis nombres de lugar, en Al-Andalus, formados de monte y un genitivo posterior, ambos de origen romance: (...) MONTE Ŷ̀̄L, sin localización precisa» ${ }^{42}$.

Quizá sea ésta la única ocasión en la que podemos admitir casi sin reservas el juicio de García de Diego López. Así, es posible pensar tanto en un originario lat. BŌN, sin diptongar, formando parte de una construcción mozárabe (*BonaAgilo), o en un masculino *Bon-Agila, como hacerlo en un ár. ibn $>$ ben, para encontrar la razón del primer componente del nombre de lugar. Pero aquí también puede servirnos el testimonio ajeno: un antropónimo del mismo tipo que el que constituye nuestro objeto - es decir, actualmente topónimo menor o nombre de despoblado-: Gilbuena ( $<$ *Egilo-Buena), donde «la aféresis inicial se vio favorecida por el desplazamiento de la sílaba tónica al entrar en composición» con el calificativo o apodo Buena, atestiguado en fuentes documentales abulenses del Medioevo ${ }^{43}$. Parece, pues, más verosímil proponer el *Bona Agilo mozárabe, conforme a la primera hipótesis de García de Diego.

CHILLA.- «De chillar, del lat. sibilare (sifilare es más popular). Acción humana» (Estudio, p. 74).

Localizado en Villamanrique, sin más datos de identificación, por el autor, que en otro lugar de su artículo (p. 21) clasifica el topónimo dentro de las «metáforas humanas auditivas», de modo consecuente con el prototipo postulado.

38 Véanse las distintas explicaciones que constata para la misma forma gil (como primero o segundo componente onomástico) a lo largo del Estudio -pp. 63, 64, 68, 80, 81, 88-.

39 Corominas aduce el étimo SENTİCELLA para los topónimos Santaella — Šenteǧella, Senteĝ̀il en fuentes árabes-y Chinchilla (cf. aquí, s. v. GERIBEL).

40 Documentada tal cual en el Estudio (p. 80), donde el autor ve Guillena ( $<$ Gilliena $<$ Giliena) como una forma «semiculta, como humiliare-humillar, pues popular sería *Gijena» (cf. la opinión de Menéndez Pidal, quien da para Guillena un étimo antroponímico QUELIUS o QUAELIUS con sufijo -ena de posesión - Toponimia Prerr., p. 132-).

41 Véase E. Tejero, Toponimia Áv., pp. 35, 114 y 141.

42 Véase en nuestra Toponimia de la Sierra Norte de Sevilla... — citada en la nota 33—, § 3.4.1.

43 Cf. E. Tejero, Toponimia Av., p. 141. 
Aún desconociendo la realidad material a que pueda denominar, fácilmente podría imaginarse un originario lat. CĔLLAM 'depósito', más tarde 'habitación de eremita’, que sería base del nombre de lugar onubense Chillas y acaso del topónimo pacense Cheles, correspondiente al término municipal de Olivenza, cercano a Alconchel (mozár. <Al-conciliu), por mucho que M. Martínez ${ }^{44}$ lo haga derivar del radical mediterráneo cala ${ }^{45}$. De otra parte, recuérdese que la evolución popular del término latino fue ciella, documentado en época medieval, y que hoy sigue perviviendo en forma cilla como término dialectal — de ésta deriva el masculino cillo 'granero'- . No se encuentra ningún obstáculo serio, por tanto, para rechazar el mozarabismo de Chilla, que, al contrario, tal vez se vea apoyado por la constatación de otro nombre de lugar de tipología aparentemente mozárabe, localizado en el término de Tomares: Chincilla (véase en el Estudio, p. 74, donde se cita sin comentar). J. Corominas (Tópica I, p. 46) sospecha para el topónimo Chinchilla - de Albacete, la Mancha y Baeza-, documentado en historiadores árabes en la forma arcaica sentegêela, un étimo SENTIC ̌̌LLA, diminutivo de SENTIX, -ICIS, 'espino', 'mata espinosa', que pasaría de SENT'CELLA a Sincélla y luego se asimilaría en $C h$-. Añádase, pues, esta otra posible etimología a la lista de soluciones mozárabes no indicadas por el autor del Estudio ${ }^{46}$, lamentablemente seguido en su elemental hipótesis por otros estudiosos. Tal ocurre con E. Tejero Robledo, quien al tratar el topónimo abulense Garganta de Chilla, justifica el segundo componente como «de chillar, lat. sifilāre 'silbar'», a pesar de encontrarlo en testimonio documental de 1189, citado «Garganta de Chiella» y «Gargantam de Chiela» ${ }^{47}$.

GERIBEL.- «Podría ser de gerifalte 'ave' del ant. nórd. geirfalki. Aplicación corriente a localidades altas, o relacionado con el ár. Gibral con metátesis». En el término de El Coronil (Estudio, p. 79).

De un étimo SILVELLA 'bosque', adjudicado por J. Corominas al Xirivella de la Huerta de Valencia - hoy pronunciado Xirvella - , que había sido alquería en otros tiempos con el nombre de Xilvella, similar al Chiriveta de la frontera catalanoaragonesa, pronunciado por determinados hablantes de la comarca Jiribeta y Jirbeta. El etimólogo encuentra la forma más cercana al origen SILV -refiriéndose al último topónimo- en la atestiguada Girbeta, y explica: «és sabut que el canvi de jé- en jí- és normal en català occidental, com en rossellonès i en valencià (...); i que l'anaptixi, darrere una $r$, d'una vocal igual a l'anterior o a la següent és un fenomen corrent a tota la Península; per tant, és clar que Giribe$t a$ ve de Girbeta i que aquest és un mer derivat de Gerb, un diminutiu»... (Estudis I, p. 198 y nota 51).

44 Véase M. Martínez Martínez, «Historia y toponimia de Olivenza», en Revista de Estudios Extremeños, t. XXXIX, n. 1 (1983), pp. 81-96.

45 Basándose en una colonización de estas tierras extremeñas por los caballeros franceses del Temple, que transplantarían aquí el nombre de la localidad francesa Chelles, población situada a las afueras de París.

46 Quien, por lo demás, parece confundir los conceptos de «andaluz» y «mozárabe» (véase el comentario a los cambios «de $c$ en $c h$ » en el Estudio, p. 14).

47 Cf. Toponimia Áv., pp. 34, 42 -notas 63 y 1, respectivamente-. 
En documento sevillano de 1506 se menciona un «donadio de xiribel alto e bajo», en el concejo de Sevilla ${ }^{48}$. Es casi seguro que corresponde al lugar denominado por el Geribel actual, lo que hace todavía más sólida la base postulada, siendo aplicable para la posterior evolución del nombre de lugar el razonamiento dado por Corominas.

GRIJA.- «Del lat. craticula 'parrilla', gradeja o gradija, graija, grija». Localizado en Lebrija (Estudio, p. 80).

Figura entre las denominaciones de lugar basadas en metáforas como «instrumento casero» (ibíd., p. 22). Muy diferente sería la motivación inicial del topónimo si resultase adecuada al lugar nombrado la base del lat. vg. ECLESૉA (clás. ECCLĒ SIA 'reunión del pueblo', 'asamblea de cristianos', 'lugar donde se celebraba') - $D E C H$, s. v. iglesia-, de la que derivarían por evolución popular el port. eigreja y el cast. medieval eglisa, egrija, frente a la voz no tradicional iglesia (véase Menéndez Pidal, Manual, pp. 59,141). De las formas antiguas dice el maestro- sólo quedan en el idioma actual los topónimos Grijalba (Burgos, Zamora) < ECLESIA ALBA y Grijota (Palencia) < ECLESIA ALTA (cf. Orígenes, p. 102). Podemos sumar a los anteriores el orónimo Sierra Grijona (con sufijo aumentativo -ona) de la provincia de Huelva, entre los municipios de Calañas y Alosno, y el sevillano Grija, único testigo aferético simple del antiguo egri$j a$, documentado por Staaf en textos leoneses del siglo XIII, según refiere Pidal (ibíd., nota a pie de página).

LAITA.- "Quizás por laitada, part. 'dañada', de *laeditare, en forma culta frente a laidar 'dañar'». En Montellano (Estudio, p. 83).

Valga para este nombre de lugar una explicación similar a la dada aquí para Badolatosa (s. v.). Compárese Laita ( < lat. LACTEM) con los topónimos Leite y Leitões de Portugal, Leitariegos y Leitoego de Asturias y Galicia, respectivamente, y sobre todo con el gascón Badlaïtouze, que mantiene el diptongo en el mismo grado de evolución (sin palatalización de ait), como Badola(i)tosa, donde la caída del elemento $i$ se deberá a etimología popular.

MENGUILLÁN.- «Del lat. mille grana, menglana, menguilán y menguillán (posiblemente)». Nombre de un cortijo del término de Carmona (Estudio, p. 86).

Dado que se trata de un nombre impuesto a una posesión, lo más lógico es que llevase el nombre del dueño o poseedor. En efecto, parece absurdo debatirse en un caos evolutivo cuando resulta de lo más sencillo pensar en un antropónimo Menguillán, compuesto de Mengo(-a) e Illán, nombres medievales harto comunes, que responden a un tratamiento popular de los nombres de persona Domingo (< lat. DOMINICUS [DIES]) y Julián ( < lat. IULIANUS). Formas variantes del primer componente constituyen parte de topónimos localizados en el norte de Sevilla: Mingo, en Pasada de Mingo Rey (Guadalcanal) y Remingo - posible apodo prefijado-, en Terrenos de Remingo (Alanís) ${ }^{49}$. J. Godoy Alcántara ${ }^{50}$

48 Donadios, p. 52.

49 Véase nuestra Toponimia de la Sierra Norte de Sevilla... (citada en la nota 33), § 3.9.

50 Ensayo histórico etimológico filológico sobre los apellidos castellanos, El Albir, Barcelona, 1980 (2. reimpr.). 
recoge las múltiples variantes romances del término domingo tomado como antropónimo: Domínigo, Domigo, Doménigo, Domencos, Domenco, Domenque, Domengue, Doménech, Mingo, Mengo, Mingones, Dominiqui, Domíniguez, Domínchez, etc. La forma femenina Menga se documenta en la temprana fecha de 1253, según Pidal ( $D L E$, p. 99,5), y reaparece como «Menga Llorente» en el $\mathrm{Li}$ bro de Buen Amor (es. 849, 939, 1004). Respecto de Illán, parece entreverse en el topónimo abulense Cillán, de «Cella (de) Julianus», documentado en Sahagún con fecha $947^{51}$ bajo la forma «Cella Illiani». Asimismo, se halla en el hagiotopónimo Sant Ylan ( $>$ Santillán) de testimonios escritos del Archivo de la Catedral de Ávila ${ }^{52}$, y puede que lo haga también en el antropónimo Domingalián, si es que éste no contiene la forma Galiano ${ }^{53}$.

2. Basten por ahora estas correcciones para dar una somera idea de lo que ha permanecido sin revisar, generalmente aceptado, durante más de cinco lustros. Dejamos para más adelante el examen de otros nombres de lugar sevillanos erróneamente interpretados y el reparo de la inexhaustividad general de los datos recogidos en el Estudio.

No nos resulta lícito, sin embargo, terminar sin expresar el interés de la obra de García de Diego López, cuya falta de cautela al proceder dando etimologías no alcanza a menoscabar ni invalidar el conjunto de materiales aportados, que no podrá ser valorado en sus justos términos antes de que se hayan efectuado otros estudios profundos sobre la materia ${ }^{54}$.

51 Véase Toponimia Áv., p. 104.

52 Ibid., pp. 202, 210.

53 Es lo que sospecha E. Tejero (Toponimia Áv., p. 81), aunque la forma documentada es idéntica a la del moderno topónimo, es decir, "Domingalian" (ibíd., p. 211), mientras que en otro lugar (véase en la p. 26) se transcribe como "Domingo Alian', que permite pensar en un segundo componente relacionado con los derivados del lat. IULIANUS (cf. Illiani, Ylán, Illán,...).

54 Mientras se imprimía este artículo, hemos hallado nuevos datos que, de un lado, ratifican las conclusiones a las que hemos llegado aquí, y, de otro, tal vez posibiliten el establecimiento de distintas hipótesis en la interpretación de algunos de los nombres estudiados(v. gr. Agualora, Alanís, Alísar, Benalíjar, Bonagil). Para su consideración, remitimos a nuestra obra ya citada, Toponimia de la Sierra Norte de Sevilla... (véase nota 33), donde pueden verse los topónimos s. vv. 
